Discussion Paper No. 05-79

\title{
Skill Biased Technological Change and Endogenous Benefits: The Dynamics of Unemployment and Wage Inequality
}

Matthias Weiss and Alfred Garloff

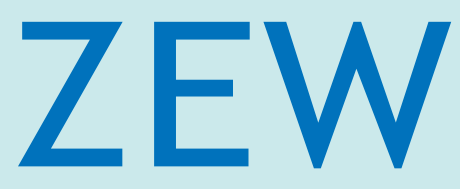

Zentrum für Europäische Wirtschaftsforschung $\mathrm{GmbH}$

Centre for European

Economic Research 
Discussion Paper No. 05-79

\title{
Skill Biased Technological Change and Endogenous Benefits: The Dynamics of Unemployment and Wage Inequality
}

\author{
Matthias Weiss and Alfred Garloff
}

Download this ZEW Discussion Paper from our ftp server:

ftp://ftp.zew.de/pub/zew-docs/dp/dp0579.pdf

Die Discussion Papers dienen einer möglichst schnellen Verbreitung von neueren Forschungsarbeiten des ZEW. Die Beiträge liegen in alleiniger Verantwortung der Autoren und stellen nicht notwendigerweise die Meinung des ZEW dar.

Discussion Papers are intended to make results of ZEW research promptly available to other economists in order to encourage discussion and suggestions for revisions. The authors are solely responsible for the contents which do not necessarily represent the opinion of the ZEW. 


\section{Nontechnical summary}

This paper studies the employment and wage dynamics under skill-biased technical change and different social welfare regimes. We show that different public schemes of poverty reduction lead to different developments in unemployment rates for the low-skilled across systems and to a different dynamics of wage dispersion. Using the social legislation of European and Anglo-Saxon countries and data from the OECD, we demonstrate these connections empirically.

We claim that one system to circumvent poverty, the European system, is such that poverty is perceived as a relative concept. Therefore, the payments of the central system to avoid poverty, social benefits, must be linked to per-capita income. Because the wage of the unskilled workers in general depends on their outside option, the unskilled workers wage is linked to social benefits and therefore to the average income. Thus, skill-biased technical change increases the wage of the unskilled because it increases the productivity of the high-skilled. This affects the average wage and thereby the unskilled workers' outside option. Unemployment of the unskilled increases because their wage increase is not justified by a respective productivity increase. On the other hand, when, as in the U.S., the poverty line does not depend on the average income, and therefore, social benefits do not depend on average income, there is no link between skill-biased technical progress and unemployment. In this system, too, the unskilled workers wage depends on the outside option. But, the outside option of the unskilled does not depend on average income and therefore not on the wage of the high-skilled workers. Wage dispersion in the form of rising real wages for the high-skilled increases, while unemployment is unchanged in the course of technological development.

Our model demonstrates that the basic intuition underlying the above argumentation is correct: in a system where benefits depend on average income, unemployment increases when the productivity of the high-skilled increases. The dispersion increases, too, but less strongly if compared to a market where benefits do not depend on average income. Thereby, we show, that the model is able to reproduce the stylized facts for the evolution of wages and employment in European and Anglo-Saxon countries over the last 20 years.

Empirically, we demonstrate, that the basic claims of the paper are correct. We show that in almost all European countries, social benefits depend on average income in one way or the other, while both for the U.S. and the UK this is not the case. Showing this, we contribute to the debate on the effect of labor market institutions and rigidities on wages and employment. 


\title{
Skill Biased Technological Change and Endogenous Benefits: The Dynamics of Unemployment and Wage Inequality*
}

\author{
Matthias Weiss ${ }^{\dagger}$ and Alfred Garloff ${ }^{\ddagger}$
}

January 3, 2006

\begin{abstract}
In this paper, we study the effect of skill-biased technological change on unemployment when benefits are linked to the evolution of average income and when this is not the case. In the former case, an increase in the productivity of skilled workers and hence their wage leads to an increase in average income and hence in benefits. The increased fallback income, in turn, makes unskilled workers ask for higher wages. As higher wages are not justified by respective productivity increases, unemployment rises. More generally, we show that skill-biased technological change leads to increasing unemployment of the unskilled when benefits are endogenous.

The model provides a theoretical explanation for diverging developments in wage inequality and unemployment under different social benefits regimes: Analyzing the social legislation in 14 countries, we find that benefits are linked to the evolution of average income in Continental Europe but not in the U.S. and the UK. Given this institutional difference, our model predicts that skill-biased technological change leads to rising unemployment in Continental Europe and rising wage inequality in the U.S. and the UK.
\end{abstract}

Keywords: Unemployment, Skill-Biased Technological Change, Wage Inequality, Benefits

JEL Classification: E24, J31, O30

${ }^{*}$ We are grateful to Philippe Aghion, Nicole Gürtzgen, Martin Hellwig, Melanie Lührmann, Lia Pacelli, Thomas Zwick, and two anonymous referees for valuable comments and suggestions and to Iliyan Stankov for excellent research assistance. The usual disclaimer applies.

${ }^{\dagger}$ MEA, Universität Mannheim, Germany, E-Mail: weiss@mea.uni-mannheim.de

‡ZEW Mannheim, Germany, E-Mail: garloff@zew.de 


\section{Introduction}

The well documented increase in wage inequality in the U.S. and the UK in the 1980s and early 1990s is attributed to a faster increase in the demand than in the supply of skills. Predominantly so-called skill-biased technological change is blamed for the rapid increase in the demand of skills 11 A broad consensus has emerged that in Europe, labor market rigidities kept the wage structure compressed so that skill-biased technological change has been leading to increasing unemployment, especially for the unskilled $\bigsqcup^{2}$ Fewer authors argue that both the stylized differences between the U.S. and Europe and the labor market rigidities used to explain these differences are overstated in the above literature (see, eg, Nickell (1997), Gregg and Manning (1997) and Nickell, Nunziata, and Ochel (2005)). Our paper contributes to the former view by providing a theoretical foundation for the dynamics of unemployment and wage inequality in the U.S. and in Continental Europe. We argue that in Europe, skill-biased technological change has adverse effects on employment of unskilled workers because their wages are linked to the skilled workers' wages. This link is established by the indexation of social benefits to per-capita income.

Modern welfare states usually possess social protection systems including schemes that provide needy people with subsistence benefits $3^{3}$ Often, the level of benefits is linked to the evolution of wages or per-capita income. The reason for this is that benefits are paid to avoid poverty so that their level must be closely related to the "subsistence level". But the subsistence level is a relative concept and so is poverty 4 In Germany, for example, the subsistence level is defined in the social legislation (Bundessozialhilfegesetz $§ 12$ BSHG, Sozialgesetzbuch $\S 27$ SGB XII). Both articles explicitly state that the subsistence level does not only consist of sufficient food, housing, clothes, furniture, etc. but also of participation in social and cultural life. Social contacts and participation in cultural life perhaps more than food, housing, and the like depend on the average wealth of a society. In societies where most of the people can afford video cameras, mobile phones, flights to distant countries, etc., a life without electric light, running water or even without a television set is considered unacceptable $5^{5}$ Therefore benefits in general depend on the average wealth

\footnotetext{
${ }^{1}$ See, eg, Gottschalk and Smeeding (1997), Berman, Bound, and Machin (1998), Katz and Autor (1999), and Acemoglu (2002). Other factors affecting the relative demand for skills that have been identified in the literature are organizational changes (eg, Lindbeck and Snower (1996) and Caroli and Reenen (2001)) and globalisation of markets (see, eg, Fenstra and Hanson (1996), Wood (1998), and Baldwin and Cain $(2000))$.

${ }^{2}$ See, eg, Krugman (1994), Katz and Autor (1999), Blau and Kahn (1996), Freeman (1996), and Acemoglu (2002).

${ }^{3}$ Names for these schemes in the different countries are "social assistance benefit", "welfare allowance", "right to the social integration", "minimum income, public assistance", "guaranteed minimum income benefit", "social benefit", "subsistence allowance", "social insertion income", "benefit in material need", etc. In the remainder of the paper, we use the label "benefits" as an umbrella term for all these schemes.

${ }^{4}$ See, eg, Foster (1998): "Absolute versus Relative Poverty" and the other contributions to the session on "What is Poverty and Who are the Poor?" in the AEA Papers and Proceedings Issue of the American Economic Review of May 1998.

${ }^{5}$ The German right-of-distraint legislation considers a television set as indispensable and excludes it
} 
of a society. The strength of this link, however, varies across countries. We find that in most of Continental Europe the level of benefits is tied closely to per-capita income while in the Anglo-Saxon countries the benefits level has been kept constant in real terms and has not been adjusted to per-capita income over the last 20 years. We show that this institutional difference is able to explain the transatlantic differences in wage and employment dynamics.

Endogeneity of the level of benefits with respect to the average income is important for labor market outcomes because it establishes a link from skilled workers' productivities to unskilled workers' wages: Changes in skilled workers productivities affect average income and thereby the level of benefits. This increase in the fallback income improves the bargaining position of the unskilled workers. In general this will result in higher wages and - for lack of respective productivity gains — higher unemployment ${ }^{6}$

The interdependence between wages and benefits yields an allocation where the wage for unskilled labor depends positively on the wage for skilled labor (even if the marginal productivities of the two factors are independent of each other). The obtained wage rigidity is a rigidity in the relation between the wages for unskilled and skilled labor. In other words, the wage for unskilled labor is too rigid with respect to the unskilled workers' productivity and it is overly sensitive to changes in the skilled workers' wages. In particular, it is shown that if - through skill-biased technological change - the productivity of the skilled workers rises faster than that of the unskilled workers, the wage of the latter increases by more than would be justified by their productivity gains. As a result, unemployment of unskilled labor increases. The matter of concern here is not that the (unskilled workers') wage falls too little - as in standard union models - but that it rises too much. This result is unique to this model where the feedback mechanism from wages to benefits and back to wages is taken into account.

To demonstrate these mechanisms, our baseline model considers a "European" economy with skilled and unskilled labor. Following papers on related issues (see, eg, Davis (1998) and Krugman (1995)), we assume that the market for skilled labor clears, while the market for unskilled labor does not 7 This classification into a competitive market from seizure.

${ }^{6}$ In fact, most benefit systems have unemployment insurance elements that depend on the level of past earnings rather than the general income level of the economy. But for two reasons, we think that unemployment insurance is not the proper measure for the fallback income of workers:

1. Unemployment insurance benefits are generally limited in duration. After a certain time limit, eligibility for unemployment insurance expires and unemployed workers receive social benefits. So, in the long run, it is social benefits that constitute the fallback income.

2. For unskilled workers, unemployment insurance benefits may easily fall short of the level of social benefits. In this case, the payment is increased to this level. So, the level of social benefits rather than the level of unemployment insurance benefits constitutes the lower bound to unskill wages.

${ }^{7}$ In Davis (1998), the wage for unskilled labor is modeled as an exogenously given fixed minimum wage while in Krugman (1995), it is assumed to be a fixed proportion of the skilled workers' wage. 
Table 1: Unemployment Rates by Education, Euro-zone, Average: 1995 - 2004

\begin{tabular}{ccc}
\hline Low Education $^{\mathrm{a}}$ & Medium Education $^{\mathrm{b}}$ & High Education $^{\mathrm{c}}$ \\
\hline $13.42 \%$ & $9.38 \%$ & $6.43 \%$ \\
\hline
\end{tabular}

Source: Eurostat; ISCED 1997 classification a) lower secondary education or less (ISCED 0-2), b) upper secondary education, post-secondary, non-tertiary education (ISCED 3-4), c) first or second stage tertiary education (ISCED 5-6).

for skilled labor and a non-competitive market for unskilled labor is somewhat in contrast to the literature on "Dual Labor Markets" (see, eg, Saint-Paul (1997)) and on "Efficiency Wages" where it is typically assumed that the market for unskilled labor is competitive and clears whereas the market for skilled labor is regulated and fails to clear. This latter view is, however, at variance with the evidence on unemployment and wage flexibility in Europe. It is the unskilled workers who are by far more likely to be unemployed which is evident from Table1. Wages are generally less flexible at the lower end of the distribution. For Germany, for example, Büttner and Fitzenberger (1998, p. 1) find that "... employees with low wages have significantly lower wage flexibility than high wage employees. This effect is particularly relevant for the lower educational groups."

Therefore, in the baseline model we assume that the wage for unskilled labor is determined by a monopolistic labor union while employment is determined by competitive firms 8 These assumptions are for simplicity. The focus of this paper is on the (strikingly large) extent to which the unskilled workers' rate of unemployment exceeds that of the skilled workers. The fact that unemployment also exists among the skilled workers might indeed be explained by considerations of insider-outsider relations, search frictions, efficiency wages, or the like. These theories might be seen as complementary rather than contradictory to this paper.

The findings of the baseline model are consistent with the evolution of wages and employment of unskilled workers in Europe over the past decades. Wages for all skill levels have risen over this period and, by and large, the employment prospects of the less skilled workers have deteriorated 9 There has been increasing consensus among economists that asymmetric technological progress and possibly increasing trade with low-wage countries

\footnotetext{
${ }^{8}$ In Section 4 this assumption is relaxed in three ways. Subsection 4.1 shows that similar results are obtained when the wage is determined in negotiations between a labor union and firms, modeled as the generalized Nash-Bargaining solution. Subsection 4.2 considers the case where the wages for both, skilled and unskilled workers are determined by unions and unemployment occurs at both skill levels. In Subsection 4.6, markets on all skill levels are assumed to be competitive.

All three modifications do not affect the results substantially.

${ }^{9}$ See, eg, Siebert (1997), Katz and Autor (1999), Cahuc and Zylberberg (2004), Chapter 2.6, or Acemoglu (2002). For Germany a detailed analysis of the employment and wage development is performed in Fitzenberger (1999).
} 
have led to a substantial shift in demand away from unskilled workers toward skilled workers during the 1980's and the 1990's. ${ }^{10}$ In the United States (and the UK), it seems, this demand shift has led to an increase in wage inequality while in (Continental) Europe, where the wage structure has remained fairly stable, it resulted in a rise in unemployment, in particular among unskilled workers (see, eg, Krugman (1994), Freeman (1995), Siebert (1997), and Davis (1998)) 11 This coincidence of rising wage inequality in the United States and rising unemployment (at rather stable relative wages) in Europe suggests that the kind of feedback mechanism described in the our baseline model has been an important feature of labor markets in Continental Europe but not in the U.S. and the UK. We show that, on the basis of only one institutional difference, namely the link between benefits and per-capita income, we can explain this difference in employment and wage dynamics.

The remainder of the paper is organized as follows. Section 2 deals with the question whether and how tightly different countries link their benefit payments to the average income for a selection of OECD countries. The model is set up in Section 3 . Comparative static results and the implications of our model with respect to the transatlantic differences in the social legislation are discussed. Section 4 assesses the robustness of the results and Section 5 summarizes and concludes.

\section{Transatlantic Differences in the Social Legislation}

In this section we analyze the legal situation both in Continental Europe and in the U.S. and the UK to demonstrate how benefits depend on per-capita income in different welfare systems. We find that in the United States and the UK benefits have not been adjusted to average income in the last 20 years, while in most European countries this adjustment is automatic and by law. Having observed this, in the next section our model shows that it is precisely this institutional difference that can account for diverging experiences in the evolution of wage inequality and unemployment.

We are aware that this binary classification into European and Anglo-Saxon countries is crude. There is substantial variation in the social legislation within these groups of countries ${ }^{12}$ But, when it comes to the evolution of benefits over time, the similarities

\footnotetext{
${ }^{10}$ Levy and Murnane (1992) and Gottschalk and Smeeding (1997) give surveys of the empirical literature on this subject.

${ }^{11}$ We are aware that the view that increasing unemployment in Continental Europe and increasing wage inequality in the U.S. and the UK are two sides of the same coin (namely skill-biased technological change) is not beyond controversy (see, eg, Nickell and Bell (1996), Gregg and Manning (1997) and Krueger and Pischke (1998)). Yet, there seems to have emerged a large consensus among many economists that this view explains at least parts of the intercontinental differences (see, eg, Cahuc and Zylberberg (2004), Chapter 10 or Borjas (2005), Chapter 11). Empirical support is given by, eg, Puhani (2003). Muysken and Zwick (2006) offer an interesting interpretation of the differences between the U.S. and Germany that is related to training costs.

${ }^{12}$ There have been several attempts in the European Union to harmonize social legislation - without much success, though. Two of the more successful attempts have led to the European Social Charter of
} 
within and the disparities between these two groups of countries are striking: In most European countries, these benefits depend on per-capita income by law, while this is not the case in Anglo-Saxon countries.

Let us consider the European countries first. In some countries, the adjustment of the benefits level over time is automatic by law, ie, there is a clear adjustment frequency and there are clear rules to what the benefits level is to be adapted. In other countries the legislation gives more scope to the government or the parliament to act and adjustments are discretionary. In some countries where there exist rules for the adjustment of benefits, the evolution of benefit payments is linked to the evolution of wages and/or income while in others, benefits are linked to consumer prices. Figure 1 contains a synopsis of the social legislation in a selection of countries. In most European countries (Austria, Denmark, Finland, Germany, Italy, Netherlands, and Portugal), welfare benefits are automatically linked to the evolution of average wages, average income or public pensions (which on their part are linked to the evolution of average wages or average income) by law. Exceptions are Belgium, France, Greece and Spain. In Greece a general income support scheme does not exist. We discuss the remaining three countries in Appendix A.1 and provide empirical evidence that is in accordance with our main hypothesis.

In Anglo-Saxon countries, on the other hand, benefits are not linked to average wages or income. In the UK, "income support" is tied to the evolution of consumer prices only. 13 In the U.S., the institutional and legal situation is more complex 14 At the federal level, the Food Stamp Program is the only program in the overall social safety net that is not restricted to certain eligibility groups. The maximum amount of food stamps that an entitled person can get is indexed to the costs of the Thrifty Food Plan, a nutritious low-cost diet (see Gundersen, LeBlanc, and Kuhn (1999), page 3). In addition, there exist special schemes for special groups: Aid to Families with Dependent Children (AFDC) provides cash payments primarily to poor single mothers. Not eligible are for example poor families with employed principal wage earners (even if they were financially eligible). The program has been replaced in 1996 by the Temporary Assistance for Needy Families (TANF) which is more restrictive in terms of duration and eligibility. The amounts granted to families have been adjusted only infrequently and very little. Between 1970 and 1993, for example, payments to a family of three have dropped by nearly $45 \%$ in real terms (see Gundersen, LeBlanc, and Kuhn (1999)). The Supplemental Security Income (SSI) is designed to help aged, blind, and disabled people, who have little or no income. The level of these payments is indexed to the COLA-Index ("Cost of Living Adjustments") ${ }^{15}$

1989 and to the social protocol annexed to the Maastricht Treaty of 1992 - both not signed by the United Kingdom. If compared to other policy areas of the European Community, the treaties on social standards remain vague.

${ }^{13}$ There were no additional discretionary increases between 1979 and 2001 (see Cantillon, Mechelen, Marx, and Bosch (2004) and Goodman and Shephard (2002).

${ }^{14}$ For a concise overview, see Uccello and Gallagher (1997) from where most of the following information is taken.

${ }^{15}$ The adjustment to the cost of living index is automatic and based on the CPI-W, the consumer price 
Finally, Medicaid provides medical assistance to poor persons, but eligibility is generally tied to eligibility for SSI or AFDC.

On the state level, the General Assistance (GA) provides income support to those poor persons who are not eligible for federal programs. Despite the common name, there is great variation across states with respect to availability, eligibility, form of benefits (cash vs. vendor payments/vouchers), duration, and the level of benefits. The program is not very generous. In all states but Nebraska, the maximum cash benefits are below the federal poverty threshold for 1995 published by the Bureau of the Census $(\$ 7,763$ for one person) ${ }^{16}$ Adjustments are rare and very low. "Eight states have enacted nominal benefit increases since 1992, but none of these have exceeded the rate of inflation. Thus, real benefit levels have remained stagnant or fallen. Six states have actually reduced nominal benefits." (Uccello and Gallagher (1997), p.5)

In summary, we can conclude, that none of the U.S. income support programs links benefits to the evolution of average income or wages. In fact, in many cases, amounts are not even adjusted for inflation.

Figure 1 in the appendix summarizes the institutional setting. It shows that welfare benefits are linked to average wages or income by law in most of Continental Europe but not in the U.S. and the UK. In Appendix A.1, we take a closer look at those European countries, that have no legal automatic link between benefits and wages or income and provide empirical evidence that is in accordance with our assumptions. The next section containing the baseline version of our model demonstrates that this institutional difference in the determination of benefits can account for diverging experiences in the evolution of employment and inequality.

\section{The Model}

\subsection{The Baseline Case: Europe}

Consider an economy with a continuum of mass 1 of homogeneous firms on an interval $[0,1]$ producing a single good. The good is produced using two input factors, unskilled and skilled labor. There is a mass 1 of workers of each type. Each worker supplies one unit of labor. For simplicity, the model is essentially static. There is no capital in the model so that consumption equals production at any point in time ${ }^{17}$

index for urban wage earners and clerical workers. In the period between 1975 and 2005, there is only one change that is above the COLA (in 1983), a legislated increase which corresponds to changes in the taxation of social benefits.

${ }^{16}$ The average percentage is $39 \%$. Missouri pays the lowest amounts (12\%).

${ }^{17}$ This allows us to focus on differences in employment and inequality that do not stem from different capital-labor ratios, as, eg, in Beaudry and Green (2003). 
Technology The firm produces according to the production function

$$
Y=\left(a_{u} \cdot l_{u}\right)^{\rho}+\left(a_{s} \cdot l_{s}\right)^{\rho}, \quad 0<\rho<1, \quad 0<a_{u}<a_{s}
$$

where $Y$ is the quantity of the final good, $l_{u}$ and $l_{s}$ are the levels of employment of unskilled and skilled labor respectively, and $\rho, a_{u}$, and $a_{s}$ are productivity parameters. This specification has the following properties:

- The elasticity of substitution between unskilled and skilled labor is $\sigma=1 /(1-\rho)>$ 1. We restrict the analysis to substitution elasticities larger than one because only in this case does skill-biased technological change have adverse effects on the relative position of the unskilled workers. Furthermore, the majority of the empirical estimates are between 1 and 2. See, eg, Autor, Katz, and Krueger (1998) who argue that a consensus estimate is a value around 1.5.

- The marginal productivities of unskilled and skilled workers are independent of each other and the cross wage elasticities of the factor demands are zero. We make this arguably strong assumption to guarantee that any relation between the wages for the two kinds of labor that arises in the model can be attributed solely to the institutional peculiarities.

These restrictions are also for simplicity. In Subsection 4.3, we consider the case of a more general CES (constant elasticity of substitution) technology. The results are shown to be independent of these different specifications.

Demand for Unskilled and Skilled Labor Firms sell their products on the world market at the world market price $P=1$ (by choice of the numéraire). At given wage levels, firms choose the level of employment so as to maximize their profit

$$
\pi=Y-w_{u} \cdot l_{u}-w_{s} \cdot l_{s} .
$$

The demand for unskilled and skilled labor is respectively

$$
l_{u}^{d}\left(w_{u}\right)=\left(\frac{\rho \cdot a_{u}^{\rho}}{w_{u}}\right)^{\frac{1}{1-\rho}} \quad \text { and } \quad l_{s}^{d}\left(w_{s}\right)=\left(\frac{\rho \cdot a_{s}^{\rho}}{w_{s}}\right)^{\frac{1}{1-\rho}},
$$

where $w_{u}$ and $w_{s}$ are the wages for unskilled and skilled labor respectively.

Benefits The model involves unemployment of unskilled workers. All unemployed individuals are assumed to receive benefits, $\tilde{w}$. In accordance with the reasoning in the introduction, the benefits are assumed to depend on the net average income

$$
\tilde{w}=\mu \cdot(1-t) \cdot \frac{Y}{2}
$$


where $Y / 2$ is the per-capita income, $t$ is the income tax rate, and $\mu \in[0,1]$ is a proportionality factor. The benefits are financed through a proportional income tax. The tax rate $t$ is endogenously determined by the government's budget constraint:

$$
\left(1-l_{u}\right) \cdot \tilde{w}=t \cdot Y
$$

The Union's Objective Function All unskilled workers are assumed to be members of a labor union. The union chooses the wage to maximize the expected labor income of its members.

$$
U=E\left[\text { net labor income } \mid w_{u}\right]=l_{u}\left(w_{u}\right) \cdot(1-t) \cdot w_{u}+\left[1-l_{u}\left(w_{u}\right)\right] \cdot \tilde{w}
$$

The first term in expression (6) represents the probability for any union member to become (or remain) employed (conditional on the wage level) times the net wage of employed unskilled workers. The second term represents the conditional probability to become unemployed times the alternative income (ie, benefits).

Wage Determination The wage for unskilled labor is assumed to be determined by a monopolistic labor union whereas the firm has the "right to manage". The union maximizes its objective function taking into account the effect of the wage level on employment. We assume that, out of idleness or lack of comprehension of the economic system, the union does not consider the second-round effects the wage has on the level of benefits and on the tax rate $\sqrt{18}$ In the formal model, this means that the objective function $(6)$ is maximized subject to (3) but taking the level of benefits $\tilde{w}$ and the tax rate $t$ as exogenously given. Solving the maximization problem yields the following result which is familiar from the literature 19

Lemma 1 Under the above assumptions, the wage for unskilled labor, $w_{u}$, is an increasing function of the level of benefits, $\tilde{w}$ :

$$
w_{u}=\frac{\tilde{w}}{\rho \cdot(1-t)} .
$$

The Interdependence of Wages and Benefits In contrast to standard union models (and in contrast to what the union takes into account), in this model, the level of benefits is a function of the net average income which, in turn, is a function of the wage for unskilled

\footnotetext{
${ }^{18}$ This assumption is also for simplicity. In Subsection 4.1. we consider the case where the union takes into full account the effects of the wage level on the level of benefits and the tax rate. The results are virtually unaffected.

${ }^{19}$ See, eg, Cahuc and Zylberberg (2004), Chapter 7, Muthoo (1999), Chapter 2.5, or Borjas (2005), Chapter 13 .
} 
labor. Accounting for this endogeneity in 7 yield $\$ 20$

$$
w_{u}^{*}=\frac{1}{2} \cdot \frac{\mu}{\rho} \cdot\left[\left(\frac{\rho \cdot a_{u}}{w_{u}^{*}}\right)^{\frac{\rho}{1-\rho}}+a_{s}^{\rho}\right] .
$$

The equilibrium wage for unskilled labor, $w_{u}^{*}$, is implicitly given by this equation ${ }^{21}$ It is easily verified that under the above assumptions, an equilibrium, $w_{u}^{*}\left(a_{u}, a_{s}, \mu, \rho\right)$, exists and is unique 22

\subsection{Comparative Statics}

The comparative static properties of the equilibrium allocation are presented in the following propositions:

Proposition 1 An increase [respectively decrease] in the unskilled workers' productivity, as measured by the productivity parameter $a_{u}$, leads to an increase [respectively decrease] in both, the equilibrium wage and the level of employment of unskilled labor.

$$
\begin{gathered}
\frac{\partial w_{u}^{*}}{\partial a_{u}} \cdot \frac{a_{u}}{w_{u}^{*}}=\frac{\eta_{Y, l_{u}}}{1-\rho+\eta_{Y, l_{u}}}>0 \\
\frac{\partial l_{u}^{*}}{\partial a_{u}} \cdot \frac{a_{u}}{l_{u}^{*}}=\frac{\rho-\eta_{Y, l_{u}}}{1-\rho+\eta_{Y, l_{u}}}>0
\end{gathered}
$$

where $\eta_{Y, l_{i}}=\frac{\partial Y}{\partial l_{u}} \cdot \frac{l_{u}}{Y}$.

A decrease in the unskilled workers' productivity leads - via a decrease in the average income - to a decrease in the unskilled workers' wage. But this decrease is less than would be required by the productivity loss because the wage is linked to the average income level which decreases by less than the unskilled workers productivity. Therefore unemployment of the unskilled increases. This failure of the wage to fully adjust to changes in productivity can be seen as a rigidity in the relative wage $w_{u} / w_{s}$.

While the wage for skilled labor always adjusts to clear the market, the wage for unskilled labor depends on the productivities of both, unskilled and skilled workers. In other words, the wage for unskilled labor is linked to the wage for skilled labor. The relative wage cannot fully adjust to changes in the relative productivity. This rigidity

\footnotetext{
${ }^{20}$ Equations $(7)$ and $(8)$ are two different ways of writing down the same result. In equation (7) the focus is on the dependency of the unskilled workers' wage on the level of (endogenous) benefits while in equation (8) the unskilled workers' wage is shown as a function of the exogenous parameters of the model.

${ }^{21}$ Throughout the paper, the term "equilibrium" will be used to refer to the allocation which results from union wage setting, given the other institutional features of the model.

${ }^{22}$ Existence: For $w_{u}$ sufficiently small (resp. sufficiently large), the right hand side of the equilibrium condition (8) is larger (resp. smaller) than the left hand side. As both sides of the equation are continuous in $w_{u}$ there must exist at least one value of $w_{u}, w_{u}^{*}$, for which both sides are equal. Uniqueness: The left hand side of (8) is strictly increasing in $w_{u}$ whereas the right hand side is strictly decreasing in $w_{u}$. Therefore, if a solution to 8 , $w_{u}^{*}$, exists, it must be unique.
} 
leads to an increase in unemployment in response to a decrease in the productivity for the unskilled workers. Similar results are obtained in standard union models where the reservation wage of the workers is exogenous.

Proposition 2 An increase [respectively decrease] in the skilled workers' productivity, as measured by the productivity parameter $a_{s}$, leads to an increase [respectively decrease] in the wage for unskilled labor and a decrease [respectively increase] in the level of employment for unskilled workers.

$$
\begin{aligned}
& \frac{\partial w_{u}^{*}}{\partial a_{s}} \cdot \frac{a_{s}}{w_{u}^{*}}=\frac{(1-\rho) \cdot \eta_{Y, l_{s}}}{1-\rho+\eta_{Y, l_{u}}}>0 \\
& \frac{\partial l_{u}^{*}}{\partial a_{s}} \cdot \frac{a_{s}}{l_{u}^{*}}=-\frac{\eta_{Y, l_{s}}}{1-\rho+\eta_{Y, l_{u}}}<0
\end{aligned}
$$

The increased productivity of the skilled workers leads to a rise in the average income. This in turn increases - through higher benefits - the unskilled workers' reservation wage and thereby their wage. Since the productivity of the unskilled workers remains unchanged, unemployment increases.

While the result in Proposition 1 - that the wage falls too little in response to a fall in the productivity of the unskilled - is also obtained in standard union models, the result in Proposition 2 - that the wage increases too much in response to a productivity gain of the skilled workers - is unique to this model where the feedback mechanism from income levels to wages is accounted for. In this model, the driving force behind both effects is the above mentioned rigidity in the relative wage.

Propositions 1 and 2 consider cases where only one type of labor becomes more productive. Depending on whose productivity increases, unemployment increases or decreases. Since in reality, technological change tends to affect the productivities of different types of labor at the same time, the question naturally arises which of the two opposite effects dominates. The following Proposition answers this question.

Proposition 3 Technological change leads to a decrease [respectively increase] in employment of the unskilled and an increase [decrease] in wage inequality whenever it leads to an increase [decrease] in $\frac{a_{s}}{a_{u}}$.

$$
\begin{gathered}
\frac{\partial l_{u}^{*}}{\partial \frac{a_{s}}{a_{u}}} \cdot \frac{\frac{a_{s}}{a_{u}}}{l_{u}^{*}}=-\frac{\eta_{Y, l_{s}}}{1-\rho+\eta_{Y, l_{u}}}<0 \\
\frac{\partial\left(\frac{w_{s}}{w_{u}}\right)^{*}}{\partial \frac{a_{s}}{a_{u}}} \cdot \frac{\frac{a_{s}}{a_{u}}}{\left(\frac{w_{s}}{w_{u}}\right)^{*}}=\frac{\rho \cdot\left(\frac{\frac{w_{s}}{w_{u}}}{\frac{a_{u}}{a_{u}}}\right)^{\frac{\rho}{1-\rho}}}{1-\rho+\left(\frac{\frac{w_{s}}{w_{u}}}{\frac{w_{s}}{a_{u}}}\right)^{\frac{\rho}{1-\rho}}}>0
\end{gathered}
$$

Skill-biased technological progress favoring the skilled workers' productivity in a way that leads to an increase in $a_{s} / a_{u}$ has a negative effect on the relative demand for unskilled 
labor, $l_{u}^{d} / l_{s}^{d}$. Since the relative wage for unskilled labor, $w_{u} / w_{s}$, cannot fully adjust to this shift in labor demand, unemployment of unskilled workers increases ${ }^{23}$ On the other hand, if the productivity of unskilled workers grows faster [or falls more slowly] than the skilled workers' productivity, the wage for unskilled labor increases [respectively falls], but by less [respectively more] than would be justified by the shift in the relative productivity so that the employment of unskilled workers increases. Any technological change that leaves the ratio $a_{s} / a_{u}$ unaffected has no effect on the level of employment.

This result is consistent with the view that it is the same factors that boost wage inequality in the U.S. and the UK and result in higher unemployment in Continental Europe. In a model in which the welfare system is less generous and wages are to a greater extent market-determined - the alleged features of U.S. and UK labor marketsskill-biased technological change (in the form of an increase in $a_{s} / a_{u}$ ) leads to a stronger increase in wage inequality while unemployment is affected less or not all. Appendix A provides detailed empirical evidence for this result.

Increasing trade with and outsourcing to low-wage countries have been cited as a second culprit of the rise in wage inequality in the United States ${ }^{24}$ In fact, in a two-sector version of this model, it can be shown that increasing trade with low-wage countries (as modeled by a decrease in the relative price of the import good-whose production is assumed to be intensive in the use of unskilled labor) has exactly the same effect on wages and employment as skill-biased technological change (as modeled by an increase in $a_{s} / a_{u}$ ). Increasing trade with low-wage countries also leads to a (downward) shift in the relative demand for unskilled labor. As the relative wage for unskilled labor does not fully adjust, unemployment of unskilled labor rises.

\subsection{Wage and Employment Dynamics: Anglo-Saxon Countries vs. Con- tinental Europe}

In this section, we explore the implications of our model for the differences in wage and employment dynamics between Anglo-Saxon countries and Continental European countries. For ease of presentation, we denote $\frac{a_{s}}{a_{u}} \equiv \alpha$ and $\frac{w_{s}}{w_{u}} \equiv \omega$ and normalize the productivity parameter of unskilled labor to 1 . The technology is thus given by $Y=l_{u}^{\rho}+\left(\alpha \cdot l_{s}\right)^{\rho}$. Benefits are given by

$$
\tilde{w}=\mu \cdot(1-t) \cdot\left(\frac{Y}{2}\right)^{\xi}
$$

where $\xi=1$ in Europe and $\xi=0$ in Anglo-Saxon countries. As expounded in Section 2 , benefits are tied to the evolution of average income in Europe, but not in the U.S. and the UK.

\footnotetext{
${ }^{23}$ It is easily verified that $\frac{\partial\left(\frac{w_{s}}{w_{u}}\right)^{*}}{\partial \frac{a_{s}}{a_{u}}} \cdot \frac{\frac{a_{s}}{a_{u}}}{\left(\frac{w_{s}}{w_{u}}\right)^{*}}=\rho \cdot\left(\frac{\frac{w_{s}}{w_{u}}}{\frac{a_{s}}{a_{u}}}\right)^{\frac{\rho}{1-\rho}} /\left(1-\rho+\left(\frac{\frac{w_{s}}{w_{u}}}{\frac{a_{s}}{a_{u}}}\right)^{\frac{\rho}{1-\rho}}\right)$ is unambiguously smaller than $\rho$, the respective elasticity that prevailed if wages were perfectly flexible.

${ }^{24}$ See, eg, Fenstra and Hanson (1996), Wood (1998) and more recently Baldwin and Cain (2000).
} 
In both regimes, the wages for unskilled and skilled labor are given by $w_{u}=\frac{\tilde{w}}{\rho \cdot(1-t)}$ and $w_{s}=\rho \cdot \alpha^{\rho}$. Taking into account the differences in the determination of benefits the relative wage for skilled labor is given by

$$
\omega_{e u}=\frac{2}{\left(\frac{\omega_{e u}}{\alpha}\right)^{\frac{\rho}{1-\rho}}+1} \cdot \frac{\rho^{2}}{\mu} \quad \text { and } \quad \omega_{a s}=\alpha^{\rho} \cdot \frac{\rho^{2}}{\mu}
$$

in European and Anglo-Saxon countries respectively. The effect of skill-biased technological change on wage inequality is given by

$$
\left(\frac{\partial \omega}{\partial \alpha} \cdot \frac{\alpha}{\omega}\right)_{e u}=\frac{\rho \cdot\left(\frac{\omega}{\alpha}\right)^{\frac{\rho}{1-\rho}}}{1-\rho+\left(\frac{\omega}{\alpha}\right)^{\frac{\rho}{1-\rho}}} \quad \text { and } \quad\left(\frac{\partial \omega}{\partial \alpha} \cdot \frac{\alpha}{\omega}\right)_{a s}=\rho
$$

It is easily shown that $\left(\frac{\partial \omega}{\partial \alpha} \cdot \frac{\alpha}{\omega}\right)_{e u}<\left(\frac{\partial \omega}{\partial \alpha} \cdot \frac{\alpha}{\omega}\right)_{a s}$ as long as $\rho<1$. The effect of skill-biased technological change on wage inequality is smaller in European countries, where the linkage of benefits to the evolution of average income keeps the wage distribution compressed.

The effects of skill-biased technological change on unemployment in European countries have been discussed in Subsection 3.2. In the Anglo-Saxon regime, employment of unskilled workers is given by $l_{u}\left(w_{u}\right)=\left(\frac{\rho}{w_{u}}\right)^{\frac{1}{1-\rho}}=\left(\frac{\rho^{2}}{\mu}\right)^{\frac{1}{1-\rho}}$. Thus (un-)employment does not depend on the relative productvitiy parameter $\alpha$. In summary, skill-biased technological change leads to an increase in unemployment in European countries and has no effect on unemployment in Anglo-Saxon countries:

$$
\left(\frac{\partial l_{u}}{\partial \alpha} \cdot \frac{\alpha}{l_{u}}\right)_{e u}=-\frac{\eta_{Y, l_{s}}}{1-\rho+\eta_{Y, l_{u}}}<0 \quad \text { and } \quad\left(\frac{\partial l_{u}}{\partial \alpha} \cdot \frac{\alpha}{l_{u}}\right)_{a s}=0
$$

\section{Robustness Considerations}

In this section, some critical assumptions of the model are relaxed or modified. The robustness of the results of the baseline model with respect to these modifications is assessed.

\subsection{Generalized Nash-Bargaining, Risk Aversion, Rational Expectations}

In this subsection, we alter the following assumptions:

- The wage is not set unilaterally by the union. It is modeled as the result of a Nash bargain between the union and the firms.

- Workers are assumed to derive decreasing marginal utility from wage income. The union's objective function is the expected utility of its members conditional on the wage level: $U=E\left[u(\right.$ net labor income $\left.) \mid w_{u}\right]=l_{u}\left(w_{u}\right) \cdot u\left[(1-t) \cdot w_{u}\right]+\left[1-l_{u}\left(w_{u}\right)\right]$. $u(\tilde{w})$, where $u(\bullet)=\ln (\bullet) 25$

\footnotetext{
${ }^{25}$ As an anonymous referee pointed out, decreasing marginal utility implies the desire for consumption smoothing over time. For simplicity we assume, that saving is not possible. The produced good must be consumed immediately. It cannot be accumulated in the form of capital.
} 
- The union and the firms take into full account the effects of the wage-setting on the level of benefits and the tax rate.

The outcome of the bargain is modeled as the Nash bargaining solution:

$$
w_{u}=\underset{w_{u}}{\arg \max }\left\{U-U_{0}\right\}^{\lambda} \cdot\left\{\pi-\pi_{0}\right\}^{1-\lambda}, \quad \lambda \in[0,1],
$$

where $U$ is the union's objective function as given in (6) and $U_{0}$ is the union's disagreement point, $\pi$ and $\pi_{0}$ are the firm's profit and disagreement point, and $\lambda$ measures the union's relative bargaining power. The union's disagreement point in the bargain, $U_{0}$, is given by the value of its objective function when the negotiation fails and all unskilled workers are unemployed,

$$
U_{0}=\ln \tilde{w} .
$$

The firm's disagreement point is given by the level of its profit when the negotiation on the wage for unskilled labor fails and only skilled workers are employed,

$$
\pi_{0}=\left(a_{s} \cdot l_{s}\right)^{\rho}-w_{s} \cdot l_{s} .
$$

In this setting, the equilibrium wage for unskilled labor is given by:

$$
w_{u}=\frac{1}{2} \cdot e^{\frac{\lambda}{\lambda+\rho \cdot(1-\lambda)} \cdot\left(\phi \cdot \eta_{Y, l_{u}}+1-\rho\right)} \cdot \mu \cdot Y, \quad \text { with } \quad \eta_{Y, l_{u}}=\frac{\partial Y}{\partial l_{u}} \cdot \frac{l_{u}}{Y}
$$

where $\phi \in\{0,1\}$ is a dummy variable indicating whether or not the second round effects of the wage for unskilled labor on the level of benefits and the tax rate are accounted for in the wage bargain ${ }^{26}$ Qualitatively, the results of Propositions 1 through 3 remain valid in this setting. For details see Appendix B.1.

Similar results are obtained if the workers' utilities depend not just on their own income but considerations of envy or fairness introduce a preference for relative wealth 27

\subsection{Unemployment at the Unskilled and the Skilled Level}

In the baseline model, we restricted unemployment to the unskilled level. This simplification was justified by the low unemployment rates for skilled workers (see table 1). In

\footnotetext{
${ }^{26}$ With $\lambda=1$ (monopoly union) and $\phi=0$ (incomplete backward induction) as in Sections 3.1 through 3.2 this implies $w_{u}=\frac{1}{2} \cdot e^{1-\rho} \cdot \mu \cdot\left[\left(\frac{\rho \cdot a_{u}}{w_{u}^{*}}\right)^{\frac{\rho}{1-\rho}}+a_{s}^{\rho}\right]$ which is very similar to the result in equation 8 . The slight difference $\left(e^{1-\rho}\right.$ instead of $\left.\frac{1}{\rho}\right)$ is due to the fact that in Subsections 3.1 through 3.2 the union is assumed to maximize expected net labor income whereas in this subsection, the union is assumed to maximize expected utility from net labor income.

${ }^{27} \mathrm{See}$, eg, Veblen (1899, p. 31): "The end sought by accumulation is to rank high in comparison with the rest of the community in point of pecuniary strength."

The role of social status is also stressed in Weiss and Fershtman (1998, p. 810): “... 'guest workers' and immigrants are less reluctant to accept low status work, partially because they do not compare themselves with local workers. In addition, it is considered less 'unfair' to pay them low wages, given the low wage in their country of origin."
} 
this subsection we show that the results are robust with respect to this simplification. We assume that both types of labor are represented by a union. The wages are determined in negotiations between the union and firms. The outcome of the negotiation is modeled as the Nash bargaining solution:

$$
w_{i}=\underset{w_{i}}{\arg \max }\left\{U_{i}-U_{i, 0}\right\}^{\lambda} \cdot\left\{\pi-\pi_{i, 0}\right\}^{1-\lambda}, \quad i \in\{u, s\}
$$

where $\pi$ is given by (2) and

$$
\begin{array}{cc}
U_{i}=l_{i}\left(w_{i}\right) \cdot(1-t) \cdot w_{i}+\left[1-l_{i}\left(w_{i}\right)\right] \cdot \tilde{w}, & U_{i, 0}=\tilde{w} \\
\pi_{i, 0}=\left(a_{j} \cdot l_{j}\right)^{\rho}-w_{j} \cdot l_{j}, \quad i, j \in\{u, s\}, & j \neq i
\end{array}
$$

In this specification, the resulting wages are

$$
w_{i}^{*}=\rho^{2 \rho-1} a_{i}^{\rho}\left(\mu \frac{\rho+(1-\rho) \lambda_{i}}{2}\left[\left(\frac{\rho+(1-\rho) \lambda_{i}}{\rho+(1-\rho) \lambda_{j}} \frac{a_{j}}{a_{i}}\right)^{\frac{\rho}{1-\rho}}+1\right]\right)^{1-\rho}, \quad i, j \in\{u, s\}, \quad i \neq j
$$

As in the baseline model, the wage for unskilled labor increases with the productivity of skilled workers. In addition, in this setting, the skilled workers' wage also increases with the unskilled workers' productivity.

Consequently, employment of unskilled labor depends on the productivity of skilled labor:

$$
l_{i}^{*}=\left(\rho^{2} \frac{\mu}{2}\left(\rho+(1-\rho) \lambda_{i}\right)\left[1+\left(\frac{\rho+(1-\rho) \lambda_{i}}{\rho+(1-\rho) \lambda_{j}} \frac{a_{j}}{a_{i}}\right)^{\frac{\rho}{1-\rho}}\right]\right)^{-1}, \quad i, j \in\{u, s\}, \quad i \neq j
$$

The results from Propositions 1 through 3 remain valid, ie:

$\frac{\partial w_{i}^{*}}{\partial a_{i}} \frac{a_{i}}{w_{i}^{*}}>0, \quad \frac{\partial l_{i}^{*}}{\partial a_{i}} \frac{a_{i}}{l_{i}^{*}}>0, \quad \frac{\partial w_{i}^{*}}{\partial a_{j}} \frac{a_{j}}{w_{i}^{*}}>0, \quad \frac{\partial l_{i}^{*}}{\partial a_{j}} \frac{a_{j}}{l_{i}^{*}}<0, \quad \frac{\partial l_{i}^{*}}{\partial \frac{a_{j}}{a_{i}}} \frac{\frac{a_{j}}{a_{i}^{*}}}{l_{i}^{*}}<0, \quad i, j \in\{u, s\}, \quad i \neq j$

\subsection{CES Technology}

In Subsections 3.1 through 3.2 , the technology is separable in the two types of labor. In this section, we consider a more general CES technology:

$$
Y=\left[\left(a_{u} \cdot l_{u}\right)^{\rho}+\left(a_{s} \cdot l_{s}\right)^{\rho}\right]^{\frac{\beta}{\rho}},
$$

where $\rho<1$ determines the elasticity of substitution $\sigma=1 /(1-\rho)$ and $\beta \in[0,1]$ is a returns-to-scale parameter. This specification nests the usual constant-returns-to-scale case $(\beta=1)$ and the specification from the previous sections $(\beta=\rho)$. Under these assumptions, the equilibrium wage for unskilled labor is given by

$$
w_{u}=\frac{1}{2} \cdot e^{-\frac{1}{\eta_{l_{u}, w_{u}}}} \cdot \mu \cdot Y,
$$


where $\eta_{l_{u}, w_{u}}=\frac{\partial l_{u}}{\partial w_{u}} \cdot \frac{w_{u}}{l_{u}}$. In Appendix B.2 it is shown that skill-biased technological change has the respective employment effects ${ }^{28}$

$$
\frac{\partial\left(1-l_{u}^{*}\right)}{\partial\left(a_{s} / a_{u}\right)} \gtreqless 0 \quad \Leftrightarrow \quad \sigma \gtreqless 1
$$

\subsection{Benefits as a Function of the Average Wage}

The central assumption of the baseline model is that benefits or, more generally, the reservation wage of unskilled workers depend on average income (see equation 4). In some countries, however, benefits are indexed to the evolution of average wages (see Appendix A.1). In addition, since other workers' wages can be observed more easily than their total income, it might be argued that the workers' reservation wage should be a function of the average wage level rather than the average income level. This reasoning takes into account the argument that workers compare their wages with the wages of the other workers as, eg, stated in the "fair wage-effort hypothesis" by Akerlof and Yellen (1990). They argue that what a worker considers her "fair wage" also depends on the wages of other workers, irrespective of their qualification ${ }^{29}$ In the model, this means that equation (4) is replaced by $\tilde{w}=\mu \cdot(1-t) \cdot \frac{w_{u} \cdot l_{u}+w_{s} \cdot l_{s}}{2}$. If the reservation wage depends on average wage the results from Sections 19 and 3.2 hold similarly: The existence of a unique equilibrium as well as the comparative static results from Propositions 1 through 3 remain valid.

\subsection{Is the Reservation Wage a Function of the Level of Benefits? Are the Benefits a Function of the Average Standard of Living?}

Two assumptions concerning the reservation wage's dependence on the average standard of living are made in Subsection 3.1. These are (i) that the reservation wage is equal to the level of benefits and (ii) that the level of benefits is a function of the average standard of living. One might consider either of them as a strong assumption. But, as long as the wage for unskilled labor depends positively on some measure of a reservation wage/fallback income that in turn is positively influenced by the average standard of living, the main conclusions remain valid. $\tilde{w}$ can be interpreted as any measure of the reservation wage that depends on the average standard of living. In fact, minimum wages are often indexed on the average wage. For example, in France, Japan, and Spain, the legal minimum wage is explicitly indexed to the average wage (see Cahuc and Zylberberg (2004), page 715). If - in addition - the minimum wage is binding, the same feedback effects are induced.

\footnotetext{
${ }^{28}$ The sign of the effect depends on the elasticity of substitution between unskilled and skilled labor. The same condition applies for the respective effects of skill-biased technological change on wage inequality in the case where wages are flexible: $\frac{w_{s}}{w_{u}}=\frac{\partial Y / \partial l_{s}}{\partial Y / \partial l_{u}}=\left(\frac{a_{s}}{a_{u}}\right)^{\rho} \cdot \quad \frac{\partial \frac{w_{s}}{w_{u}}}{\partial \frac{a_{s}}{a_{u}}}=\rho \cdot\left(\frac{a_{s}}{a_{u}}\right)^{\rho-1} \gtreqless 0 \quad \Leftrightarrow \quad \sigma \gtreqless 1$. See, eg, Acemoglu (2002) for a discussion of this issue.

${ }^{29}$ See also footnote 27
} 


\subsection{Competitive Market for Unskilled Labor}

Most of the previous subsections relied on the assumption that the wage for unskilled labor is set by a labor union while the wage for skilled labor is flexible and clears the market. In some European countries, however, wages at the very bottom of the wage distribution are not covered by unions and it has been argued that the market for unskilled labor is rather competitive (see Saint-Paul (1997)). In this section, we argue that our results are robust with respect to these considerations.

Consider the following modified version of the economy in Subsection 3.1. Assume that the workforce consists of a continuum of mass 1 of heterogeneous workers indexed by skill-level $i \in[0,1]$. The technology of the firm is $Y=\int_{0}^{1} a_{i} \cdot l_{i}^{\rho} \cdot \mathrm{d} i$, where $l_{i}$ is employment of workers of skill type $i$. Assume that wages for all skills be perfectly flexible so that labor markets at all skill levels clear. Assume further - as in Subsection 3.1 that each worker inelastically supplies one unit of labor whenever the prospective wage exceeds the level of welfare aid. Equilibrium wages are given by $w_{i}=\frac{\partial Y}{\partial l_{i}}=\rho \cdot a_{i} 30$

Assume that, in order to guarantee the subsistence level, the government pays social benefits to those workers whose wage is below a certain threshold. These benefits are financed by an income tax. Following the considerations in the introduction, the subsistence level is a relative concept and so benefits depend on the average income level $\tilde{w}=\mu \cdot \bar{y}=\mu \cdot \int_{j}^{1} a_{i} \cdot \mathrm{d} i$, where $j$ is the marginal worker (or skill type) whose marginal productivity is exactly equal to the level of benefits. For workers with types higher than $j$, working pays. Workers with types lower than $j$ prefer to receive social benefits. $j$ is the marginal worker who is indifferent between working and unemployment. $j$ is implicitly given by $w_{j}=a_{j} \cdot \rho \stackrel{!}{=} \tilde{w}=\mu \cdot \int_{j}^{1} a_{i} \cdot \mathrm{d} i$.

Assume for simplicity that $a_{i}$ be uniformly distributed over the interval $\left.[\underline{a}, \bar{a}]\right]^{31}$ The marginal worker is then determined by

$$
j=\frac{\rho \cdot\left(1-\frac{\bar{a}}{a}\right)-\mu+\sqrt{\rho^{2} \cdot\left(1-2 \cdot \frac{\bar{a}}{a}\right)+\left(\rho^{2}+\mu^{2}\right) \cdot\left(\frac{\bar{a}}{a}\right)^{2}}}{\mu \cdot\left(\frac{\bar{a}}{\underline{a}}-1\right)} .
$$

From the definition of $j$ follows that $j$ is equal to the rate of unemployment ${ }^{32}$ As in Subsection 3.2 , we now analyze the effects of technological progress on the level of unemployment. Technological progress affects the productivities of the workers. The (uniform) distribution of skills is determined by the upper and lower bounds $\bar{a}$ and $\underline{a}$. A proportionate increase in both implies that the productivities of all workers increase at the same rate.

\footnotetext{
${ }^{30}$ Again, the final good is chosen as numéraire.

${ }^{31}$ The productivity level of a type $i$ worker is then given by $a_{i}=\underline{a}+(\bar{a}-\underline{a}) \cdot i$.

${ }^{32}$ To be exact, the rate of unemployment is $u=\max \{0, j\}$. If $j$ is negative, even the least skilled worker prefers to work and there is no unemployment. The condition for unemployment in this setting is: $j>0$ $\Leftrightarrow \mu>2 \cdot \rho /\left(\frac{\bar{a}}{\underline{a}}+1\right)$. Unemployment occurs only if the replacement rate of unemployment benefits is sufficiently high relative to the productivity parameters.
} 
A more than proportionate increase of the upper bound $\bar{a}$ relative to the lower bound $\underline{a}$ (ie, an increase in $\bar{a} / \underline{a}$ ) implies that productivities of workers with higher skills increase faster than productivities of workers with lower skills (ie, $a_{i} / a_{i^{\prime}}$ increases for any pair $i>i^{\prime}$ ).

It is straightforward to show that unemployment decreases with an increase in $\underline{a}$ (this is the equivalent to Proposition 1) and increases with an increase in $\bar{a}$ (this is the analogue to Proposition 22. More generally, unemployment increases if and only if $\bar{a} / \underline{a}$ increases. This finding corresponds directly to the result in Proposition 3. Thus, as in Subsection 3.2 . whenever technological progress is skill-biased, favoring the productivities of the relatively more skilled, unemployment increases.

This illustrates that the results obtained in Subsection 3.2 do not depend on the specification of the wage determination. In fact, even with perfectly competitive labor markets, (voluntary) unemployment can increase in the face of technological change. All that is required is that the worker's reservation wage is linked to the average income level and that technological change is skill-biased 33

\section{Summary and Conclusion}

In this paper, we study the effects of skill-biased technological change on unemployment when benefits are linked to per-capita income. This link to per-capita income introduces a tie between the wages for different skills.

In standard models of union wage setting, wages - especially at the lower end of the wage distribution - depend on the level of unemployment or social security benefits (which constitute the workers' reservation wage). As a consequence, these wages are downwardly rigid. This rigidity causes unemployment when productivity falls and wages do not adjust sufficiently. In our paper, benefits are endogenous and depend on wages. The interdependence between wages and benefits yields an allocation where the wage for unskilled labor depends positively on the wage for skilled labor. The obtained wage rigidity is a rigidity in the relation between the wages for unskilled and skilled labor. The wage for unskilled labor is too rigid with respect to the unskilled workers' productivity and it is overly sensitive to changes in the skilled workers' productivity.

If - as a result of skill-biased technological change - the productivity of the skilled workers rises faster than that of the unskilled workers, the wage of the latter increases by more than would be justified by their productivity gains because it is linked to the skilled workers' wage via the benefits. As a result, unemployment of unskilled labor increases. The matter of concern here is not that the unskilled workers' wage falls too little - as in standard union models - but that it rises too much.

\footnotetext{
${ }^{33}$ This example might be a better model for some European labor markets where wages at the lower end of the wage distribution are not covered by union wage bargaining but - contrary to anglo-saxon economies - the social security system is rather generous.
} 
The findings of this paper are consistent with the evolution of wages and employment of unskilled workers in Europe over the past decades. Wages for all skill levels have risen over this period and, by and large, the employment prospects of the less skilled workers have deteriorated.

Comparing the social legislation in the U.S. and many European countries, we find that benefits are linked to the evolution of average income or wages in Continental Europe but not in the U.S. and the UK. Given this institutional difference, our model predicts that skill-biased technological change leads to rising unemployment in Continental Europe and rising wage dispersion in the U.S. and the UK.

We can deduce interesting policy implications from the model. Any increase in the relative productivity (or more generally in the relative "market value") of skilled workers leads to a higher rate of unemployment the European model - even if the absolute productivity of unskilled workers increases as well, but less than proportionately. From the point of view of the model, we can blame two factors for the high unemployment of the unskilled. First, benefits are tied to the average income and second, benefits are a determinant of the wage of the unskilled. So, any policy measure that aims at weakening either of these links will decrease unemployment. It is to be noted, however, that our model does not alter a principal insight in the literature, namely the tradeoff between wage inequality and unemployment. A decrease in unemployment would come at the cost of higher wage inequality. There might be possibilities, however, to overcome this dilemma. One way might be the introduction of a negative income tax. Such a tax scheme allows the uncoupling of gross from net wages. Gross wages (and thus wage costs for firms) are determined by market forces and reflect productivities and at the same time, inequality in net wages can be kept from growing. These wage subsidies to unskilled workers would have to be financed of course, but as these workers would not earn benefits anymore, the government's budget might even be relieved. 


\section{Appendix}

\section{A Empirical Evidence}

\section{A.1 The Link Between Benefits and Per-Capita Income}

To confirm our main hypothesis, in Section 2 we look at the legislation of 14 countries (see Figure 1). For 10 countries the legal situation is clear and confirms our crude classification in "European" and "Anglo-Saxon" countries. In three "European" countries Belgium, France, and Spain, benefits are not linked automatically to the average income or wages. Partly the law itself envisions that there are additional discrete adjustments. This is the case for example in Belgium. There, the law explicitly allows the king to adjust the benefit payments to the development of the living standards. As the legal situation allows these countries to be "European" and "Anglo-Saxon", we choose an empirical assessment to uncover the connection between average wages and benefit levels. For various reasons direct data on benefit levels are not available: In general, benefit payments depend on individual characteristics (wealth, income, household size, etc.) and differ across regions. Furthermore, in-kind transfers often make up an important part of total benefits. Therefore, we use data on (real) social expenditures on unemployment per unemployed from the OECD to approximate the benefit payments. We take the social expenditures on unemployment as a proxy for expenditures on benefits and take the number of unemployed individuals (from the OECD) as a proxy for the number of benefit recipients ${ }^{34}$ Table 2 reports results from regressions of changes in real social expenditures on unemployment per unemployed on real GDP per capita changes 35 The influence is significant and roughly of the same magnitude for all three countries 36 The purpose of these regressions is modest, however: We use the best information we could assemble and get results that are at least consistent with our classification.

In summary, we conclude that there is a positive relationship between our proxy for benefits and average income in the three "European" countries, where the legal situation

\footnotetext{
${ }^{34}$ We use social expenditures on unemployment, since a category for benefits alone does not exist so that this category comes closest to our needs. Using in addition social expenditures on housing and incapacity-related benefits does not change the principal conclusions. Results are available upon request.

${ }^{35}$ It is likely that both real GDP per capita and real social expenditures per unemployed are trended. We use first differences in order not to run into the problem of a spurious regression.

${ }^{36}$ To assess the quality of our proxy social expenditures for unemployment per unemployed, we run the same regression for Germany, the U.S., and the UK where we know the administrative rules. As expected for Germany we get the significantly positive influence while for the U.S and the UK we do not. In addition, we perform the above regressions for the other countries. Most results are as we expect. However, one permanent exception is Italy which does not seem to be a "European" country and where the effect is almost always negative and often even significant.
} 


\begin{tabular}{|c|c|c|c|}
\hline 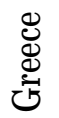 & 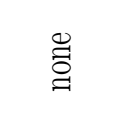 & 1 & 1 \\
\hline 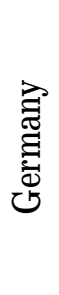 & 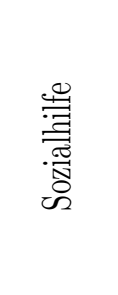 & 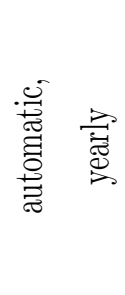 & 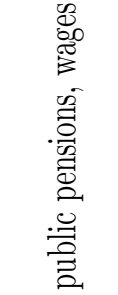 \\
\hline $\begin{array}{l}\vec{\Xi} \\
\underset{\Xi}{\Xi} \\
\text { 茎 }\end{array}$ & 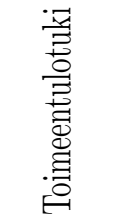 & 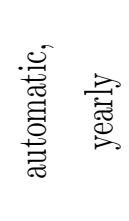 & 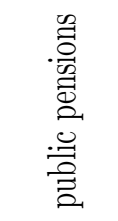 \\
\hline 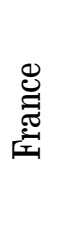 & 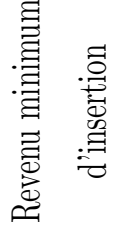 & 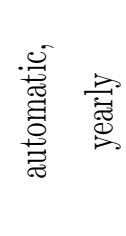 & 己 \\
\hline 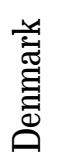 & 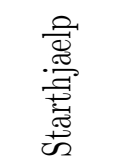 & 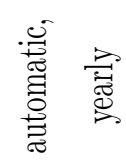 & 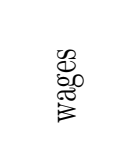 \\
\hline 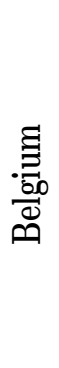 & 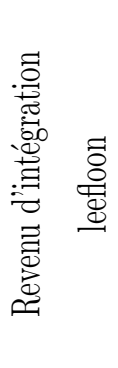 & 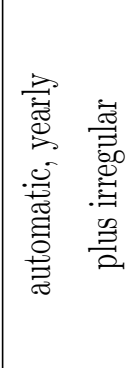 & 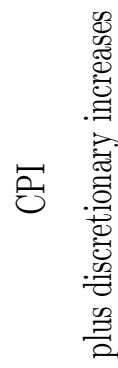 \\
\hline 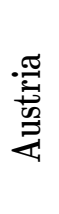 & $\begin{array}{l}\text { 营 } \\
\text { : } \\
\text { 忽 }\end{array}$ & 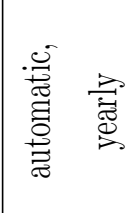 & 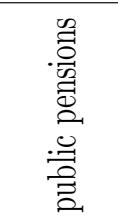 \\
\hline $\begin{array}{l}\text { 䒿 } \\
\text { 吾 }\end{array}$ & 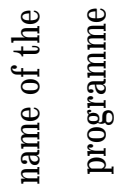 & 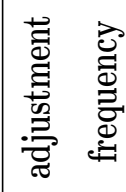 & 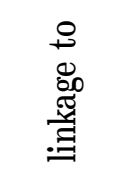 \\
\hline
\end{tabular}

\begin{tabular}{|c|c|c|c|}
\hline 岕 & 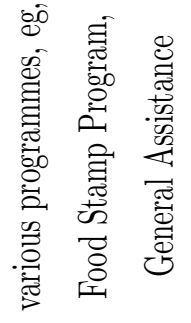 & 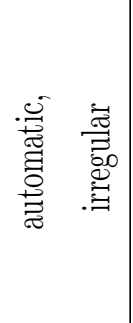 & 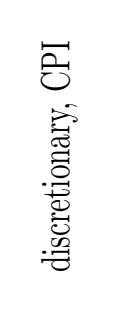 \\
\hline 岁 & 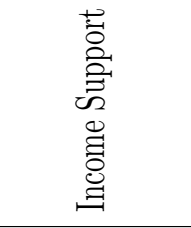 & 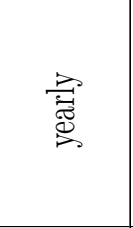 & છี \\
\hline 离 & 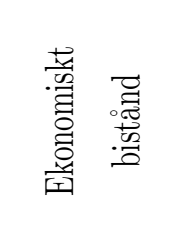 & 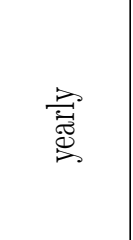 & 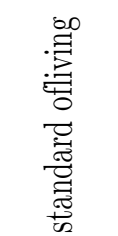 \\
\hline 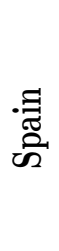 & 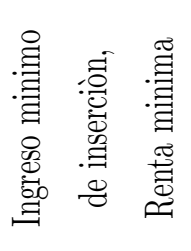 & 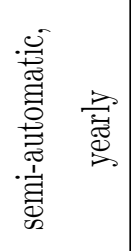 & 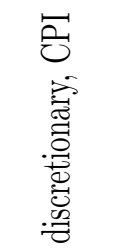 \\
\hline 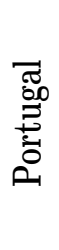 & 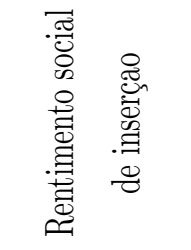 & 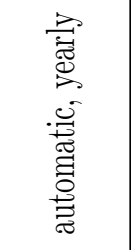 & 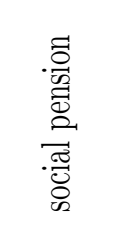 \\
\hline 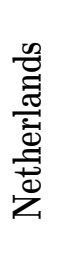 & 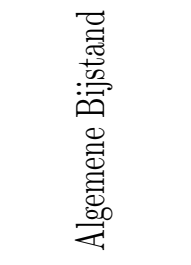 & 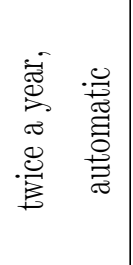 & 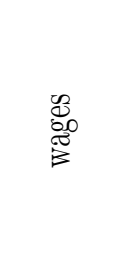 \\
\hline 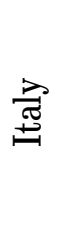 & 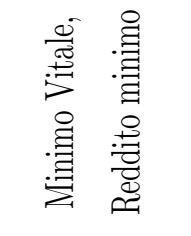 & 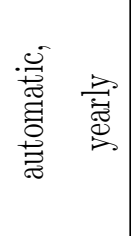 & 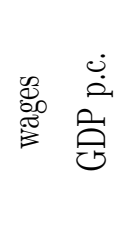 \\
\hline 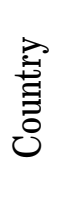 & 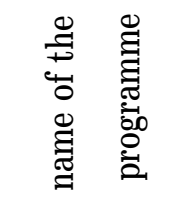 & 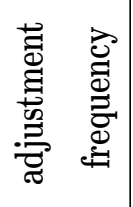 & 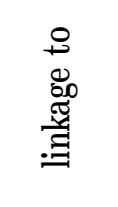 \\
\hline
\end{tabular}

Figure 1: Social Security in "Anglo-Saxon" and in "European" Countries

Source: Cantillon, Mechelen, Marx, and Bosch (2004) and MISSOC (Mutual Information System on Social Protection in the EU Member States and the EEA): http://europa.eu.int/comm/employment_social/social_protection/index_en.html. 
Table 2: Relationship between real GDP per capita and real social expenditures on unemployment per unemployed, 1980-2001

Dependent Variable: Real Social Expenditures per Unemployed

\begin{tabular}{l|ccc}
\hline & Belgium & France & Spain \\
\hline Real GDP per Capita & 0.955 & 1.265 & 1.219 \\
& $(0.435)$ & $(0.419)$ & $(0.592)$ \\
\hline
\end{tabular}

All variables in first differences and national currency.

Standard errors in parentheses.

is not unique.

As very briefly discussed in Subsection 4.5, a minimum wage that depends on average wages has a similar effect as benefits that depend on average wages. This is the case in France and Spain, where the minimum wage is tied to average income by law. So, for these two countries there is an additional link between the wage of the unskilled and the wage of high-skilled, even when, as in France, the benefits are not tied to the average income by law. A minimum wage that is tied to average income also induces adverse employment effects of skill-biased technological change. Again, for the U.S. and the UK this link does not exist. In the U.S., the minimum wage has not even been adjusted to consumer prices. In 2000 the minimum wage was $25 \%$ lower in real terms than in 1978 (see Card and DiNardo (2002), Figure 22). In the UK, a national minimum wage has only been introduced in 1999 and can therefore not account for changes in inequality and employment in the 1980s and 90s.

\section{A.2 Descriptive Evidence to Proposition 3}

Proposition 3 states that skill-biased technological change leads to rising wage inequality and rising unemployment in European countries because the relative wage cannot fully adjust to changes in relative labor demand. Put differently: If the wage dispersion in Europe rises, it does not rise enough and unemployment rises as well. The unemployment rate should thus be positively correlated with the skill-premium in Europe. A regression of the unemployment rate of the unskilled individuals, $u_{u, t}$, on the skill premium for Germany, 1975 - 2004 yields:

$$
\widehat{u_{u, t}}=\underset{(33.884)}{-162.133}+\underset{(15.722)}{82.171} \cdot \frac{w_{s, t}}{w_{u, t}} \quad\left(R^{2}=0.4938\right)
$$


where standard errors are given in parentheses 37 This substantiates the theoretical result in Proposition $33^{38}$

For the "Anglo-Saxon" model, we expect a zero correlation between wage dispersion and unemployment of the unskilled, since wages of the unskilled do not react to changes in the wages of the skilled. If the wage dispersion increases, it increases enough to adjust to changes in relative labor demand. Unemployment remains unchanged while wage dispersion increases. A regression of the unemployment rate of the unskilled, $u_{u, t}$, on the skill premium for the U.S., 1975 - 2003 yields 39

$$
\widehat{u_{u, t}}=\underset{(2.231)}{9.997}+\underset{(0.650)}{0.013} \cdot \frac{w_{s, t}}{w_{u, t}} \quad\left(R^{2}=0.0000\right)
$$

where again standard errors are given in parentheses. Here, the relation between the wage premium and unemployment is insignificant, as we expected. ${ }^{40}$

\section{B Proofs, Derivations, etc.}

\section{B.1 The Nash-Bargaining Solution}

Subsection 4.1 considers the case where the wage is determined in negotiations between the union and firms. The outcome of the negotiation is modeled as the general NashBargaining solution and is given by:

$$
w_{u}^{*}=e^{\frac{\lambda}{\lambda+\rho \cdot(1-\lambda)} \cdot\left(\frac{\phi \cdot \rho \cdot\left(\frac{\rho \cdot a_{u}}{w_{u}^{*}}\right)^{\frac{\rho}{1-\rho}}}{\left(\frac{\rho \cdot a_{u}}{w_{u}^{*}}\right)^{\frac{\rho}{1-\rho}}+a_{s}^{\rho}}+1-\rho\right)} \cdot \mu \cdot \frac{\left(\frac{\rho \cdot a_{u}}{w_{u}^{*}}\right)^{\frac{\rho}{1-\rho}}+a_{s}^{\rho}}{2}
$$

Comparative statics with respect to the productivity parameters yield:

$$
\frac{\partial w_{u}}{\partial a_{u}} \cdot \frac{a_{u}}{w_{u}}=\frac{\eta_{Y, l_{u}} \cdot\left[\eta_{Y, l_{u}}+\left(1+\phi \cdot \rho \cdot \frac{\lambda}{\lambda+\rho \cdot(1-\lambda)}\right) \cdot \eta_{Y, l_{s}}\right]}{\rho \cdot(1-\rho)+\eta_{Y, l_{u}} \cdot\left[\eta_{Y, l_{u}}+\left(1+\phi \cdot \rho \cdot \frac{\lambda}{\lambda+\rho \cdot(1-\lambda)}\right) \cdot \eta_{Y, l_{s}}\right]}>0
$$

\footnotetext{
${ }^{37} w_{u}$ is the wage for unskilled workers as categorized by the lowest performance group of blue-collar workers ("Leistungsgruppe 3, Arbeiter"). $w_{s}$ is the wage for skilled workers as categorized by the highest performance group of white-collar workers ("Leistungsgruppe 2, Angestellte"), Source: German Federal Statistical Office. Unemployment rates by qualification are from Reinberg and Hummel (2002) and Reinberg and Hummel (2005).

${ }^{38}$ The finding that higher wage dispersion and unemployment are positively correlated (across age-byeducation cells) in Germany is also found and discussed by Fitzenberger and Garloff (2005).

${ }^{39}$ Unemployment rates by educational attainment stem from U.S. Census Bureau (1975 - 2004) and Francesconi, Orszag, Phelps, and Zoega (1998). Wages stem from the CPS (U.S. Census Bureau, internet release, www.census.gov/hhes/www/income/histinc/incpertoc.html).

${ }^{40}$ Unemployment of the unskilled and wage dispersion are unlikely to contain a trend. While this is obvious for the unemployment rate at least in an asymptotic sense, it is plausible for wage dispersion, too. Nevertheless, we performed the same regression in first differences. Albeit less strongly, the regression results remains significant for Germany (and insignificant for the United States).
} 


$$
\begin{gathered}
\frac{\partial l_{u}}{\partial a_{u}} \cdot \frac{a_{u}}{l_{u}}=\frac{\left(1-\frac{\lambda}{\lambda+\rho \cdot(1-\lambda)} \cdot \phi \cdot \eta_{Y, l_{u}}\right) \cdot \eta_{Y, l_{s}}}{1-\rho+\eta_{Y, l_{u}} \cdot\left(1+\frac{\lambda}{\lambda+\rho \cdot(1-\lambda)} \cdot \phi \cdot \eta_{Y, l_{s}}\right)}>0 \\
\frac{\partial w_{u}}{\partial a_{s}} \cdot \frac{a_{s}}{w_{u}}=\frac{\eta_{Y, l_{s}} \cdot\left(1-\frac{\lambda}{\lambda+\rho \cdot(1-\lambda)} \cdot \phi \cdot \eta_{Y, l_{s}}\right)}{1+\frac{\eta_{Y, l_{u}}}{1-\rho} \cdot\left(1+\frac{\lambda}{\lambda+\rho \cdot(1-\lambda)} \cdot \phi \cdot \eta_{Y, l_{s}}\right)}>0 \\
\frac{\partial l_{u}}{\partial a_{s}} \cdot \frac{a_{s}}{l_{u}}=\frac{\partial l_{u}}{\partial \frac{a_{s}}{a_{u}}} \cdot \frac{\frac{a_{s}}{a_{u}}}{l_{u}}=-\frac{\left(1-\frac{\lambda}{\lambda+\rho \cdot(1-\lambda)} \cdot \phi \cdot \eta_{Y, l_{u}}\right) \cdot \eta_{Y, l_{s}}}{1-\rho+\eta_{Y, l_{u}} \cdot\left(1+\frac{\lambda}{\lambda+\rho \cdot(1-\lambda)} \cdot \phi \cdot \eta_{Y, l_{s}}\right)}<0
\end{gathered}
$$

An increase in the unskilled workers productivity $a_{u}$ leads to an increase in both employment of and wages for unskilled labor. This result corresponds to Proposition 1. An increase in the skilled workers productivity $a_{s}$ leads to an increase in the wage for unskilled labor and a decrease in unskilled employment. This result corresponds to Proposition 2. Skill-biased technological change (an increase in $a_{s} / a_{u}$ ) leads to a decrease in employment. This result corresponds to Proposition 3.

\section{B.2 CES Technology}

Subsection 4.3 considers the case where the firm's technology is of the more general CES type:

$$
Y=\left[\left(a_{u} \cdot l_{u}\right)^{\rho}+\left(a_{s} \cdot l_{s}\right)^{\rho}\right]^{\frac{\beta}{\rho}}
$$

In this case, the equilibrium wage for and employment of unskilled labor are given by:

$$
w_{u}=\frac{1}{2} \cdot e^{-\frac{1}{\eta_{l_{u}, w_{u}}}} \cdot \mu \cdot Y \quad l_{u}=\frac{2}{\mu} \cdot \eta_{Y, l_{u}} \cdot e^{\frac{1}{\eta_{l_{u}, w_{u}}}}
$$

Employment effects of skill-biased technological change can be derived as:

$$
\frac{\partial l_{u}}{\partial a} \frac{a}{l_{u}}=-\rho \frac{\left(\frac{\frac{1}{1-\beta}-\frac{1}{1-\rho}}{\left(\frac{1}{1-\beta}+\frac{1}{1-\rho} \theta\right)^{2}}(1+\theta)+1\right) \frac{\theta}{1+\theta}}{1-\rho\left(\frac{\frac{1}{1-\beta}-\frac{1}{1-\rho}}{\left(\frac{1}{1-\beta}+\frac{1}{1-\rho} \theta\right)^{2}}(1+\theta)+1\right) \frac{\theta}{1+\theta}} \gtreqless 0 \quad \Leftrightarrow \quad \rho \lesseqgtr 0
$$

where $\theta=\left(\frac{a_{s}}{a_{u} l_{u}}\right)^{\rho}$. Skill-biased technological change has adverse employment effects for the unskilled if the elasticity of substitution between unskilled and skilled labor is larger than 1. If unskilled and skilled labor are complements $(\rho<0)$, employment increases in the presence of skill-biased technological change.

Proof. A sufficient condition for the above inequality to hold is that the numerator $\frac{\frac{1}{1-\beta}-\frac{1}{1-\rho}}{\left(\frac{1}{1-\beta}+\frac{1}{1-\rho} \theta\right)^{2}} \theta+\frac{\theta}{1+\theta}$ and the denominator $1-\rho\left(\frac{\frac{1}{1-\beta}-\frac{1}{1-\rho}}{\left(\frac{1}{1-\beta}+\frac{1}{1-\rho} \theta\right)^{2}} \theta+\frac{\theta}{1+\theta}\right)$ are both positive.

For $\rho \leq 0$, this is obvious. (Remember that $\beta \in[0,1]$.)

$\rho>0$ : 


\section{Sign of the numerator:}

$$
\left(\frac{1}{1-\beta}-\frac{1}{1-\rho}\right) \frac{(1+\theta)}{\left(\frac{1}{1-\beta}+\frac{1}{1-\rho} \theta\right)^{2}}+1 \stackrel{?}{>} 0
$$

For $\beta>\rho$, the numerator is obviously positive.

For $\beta<\rho,\left(\frac{1}{1-\beta}-\frac{1}{1-\rho}\right) \frac{(1+\theta)}{\left(\frac{1}{1-\beta}+\frac{1}{1-\rho} \theta\right)^{2}}$ is most negative, when $\frac{(1+\theta)}{\left(\frac{1}{1-\beta}+\frac{1}{1-\rho} \theta\right)^{2}}$ is largest. Because $\frac{\partial \frac{(1+\theta)}{\left(\frac{1}{1-\beta}+\frac{1}{1-\rho} \theta\right)^{2}}}{\partial \theta}<0, \frac{(1+\theta)}{\left(\frac{1}{1-\beta}+\frac{1}{1-\rho} \theta\right)^{2}}$ is largest when $\theta$ is smallest, ie, $\theta=1$ :

$$
\begin{gathered}
\left(\frac{1}{1-\beta}-\frac{1}{1-\rho}\right) \frac{(1+\theta)}{\left(\frac{1}{1-\beta}+\frac{1}{1-\rho} \theta\right)^{2}}+1=\frac{2\left(\frac{1}{1-\beta}-\frac{1}{1-\rho}\right)+\left(\frac{1}{1-\beta}+\frac{1}{1-\rho}\right)^{2}}{\left(\frac{1}{1-\beta}+\frac{1}{1-\rho}\right)^{2}}>0 \\
\Leftrightarrow \quad \beta=\frac{2+\frac{1}{1-\rho}-\sqrt{1+4 \frac{1}{1-\rho}}}{1+\frac{1}{1-\rho}-\sqrt{1+4 \frac{1}{1-\rho}}}>1
\end{gathered}
$$

This means that the numerator can never be negative. Even with $\theta=1, \beta$ would have to be larger than 1 for $\left(\frac{1}{1-\beta}-\frac{1}{1-\rho}\right) \frac{(1+\theta)}{\left(\frac{1}{1-\beta}+\frac{1}{1-\rho} \theta\right)^{2}}+1$ to become negative.

This establishes that the numerator is positive.

\section{Sign of the Denominator}

$$
1-\rho \underbrace{\left(\frac{\frac{1}{1-\beta}-\frac{1}{1-\rho}}{\left(\frac{1}{1-\beta}+\frac{1}{1-\rho} \theta\right)^{2}} \theta+\frac{\theta}{1+\theta}\right)}_{>0} \stackrel{?}{>} 0
$$

The second part of the left hand side of the inequality is increasing with $\theta$ :

$$
\frac{\partial \rho\left(\frac{\frac{1}{1-\beta}-\frac{1}{1-\rho}}{\left(\frac{1}{1-\beta}+\frac{1}{1-\rho} \theta\right)^{2}} \theta+\frac{\theta}{1+\theta}\right)}{\partial \theta}>0 .
$$

Because the inequality holds even for $\theta \rightarrow \infty$ :

$$
\lim _{\theta \rightarrow \infty} 1-\rho\left(\frac{\frac{1}{1-\beta}-\frac{1}{1-\rho}}{\left(\frac{1}{1-\beta}+\frac{1}{1-\rho} \theta\right)^{2}} \theta+\frac{\theta}{1+\theta}\right)=1-\rho>0
$$

it must hold for all possible values of $\theta$. This establishes that the denominator is positive. 


\section{References}

Acemoglu, D. (2002): "Technical Change, Inequality, and the Labor Market," Journal of Economic Literature, 40, 7-72.

Akerlof, G. A., And J. L. Yellen (1990): "The Fair Wage-Effort Hypothesis and Unemployment," Quarterly Journal of Economics, 105(2), 256-283.

Autor, D. H., L. F. Katz, and A. B. Krueger (1998): "Computing Inequality: Have Computers Changed the Labor Market?," Quarterly Journal of Economics, 113(4), 1169 $-1213$.

Baldwin, R. E., and G. G. Cain (2000): "Shifts in Relative U.S. Wages: The Role of Trade, Technology, and Factor Endowments," Review of Economics and Statistics, $82(4), 580-595$.

Beaudry, P., and D. Green (2003): "The Changing Structure of Wages in the US and Germany: What Explains the Difference?," American Economic Review, 93(2), $573-603$.

Berman, E., J. Bound, And S. Machin (1998): "Implications of Skill-Biased Technological Change: International Evidence," Quarterly Journal of Economics, 113(4), $1245-1279$.

Blau, F. D., And L. M. Kahn (1996): "International Differences in Male Wage Inequality: Insitutions versus Market Forces," Journal of Political Economy, 104(4), 791-836.

BorJas, G. J. (2005): Labor Economics. McGraw-Hill, Boston.

Büttner, T., And B. Fitzenberger (1998): "Central Wage Bargaining and Regional Wage Rigidity: Evidence from the Entire Wage Distribution," Discussion Paper No. 98-39, Centre for European Economic Research (ZEW), Mannheim.

Cahuc, P., And A. Zylberberg (2004): Labor Economics. Mit Press, Cambridge.

Cantillon, B., N. V. Mechelen, I. Marx, and K. V. D. Bosch (2004): "The Evolution of Minimum Income Protection in 15 European Countries, 1992-2001," mimeo.

Card, D., and J. E. DiNardo (2002): "Skill Biased Technological Change and Rising Wage Inequality: Some Problems and Puzzles," Journal of Labor Economics, 20(4), 733-783.

Caroli, E., And J. V. Reenen (2001): "Skill Biased Organizational Change? Evidence from a Panel of British and French Establishments," Quarterly Journal of Economics, 116(4), 1449-1492.

Davis, D. R. (1998): "Does European Unemployment Prop Up American Wages?," American Economic Review, 88(3), 478-494. 
Fenstra, R. C., and G. H. Hanson (1996): "Globalization, Outsourcing, and Wage Inequality," American Economic Review, 86, 240-245.

Fitzenberger, B. (1999): Wages and Employment Across Skill Groups: An Analysis for West Germany. Physica, Heidelberg.

Fitzenberger, B., And A. Garloff (2005): "Unemployment, Labor Market Transitions and Residual Wage Dispersion," Discussion Paper No. 05-04, Centre for European Economic Research (ZEW), Mannheim.

Foster, J. E. (1998): "Absolute versus Relative Poverty," American Economic Review, $88(2), 335-341$.

Francesconi, M., J. M. Orszag, E. S. Phelps, and G. Zoega (1998): "Education and the Natural Rate of Unemployment," mimeo.

Freeman, R. (1995): “Are Your Wages Set in Beijing?, Journal of Economic Perspectives, 9(3), 15-23.

Freeman, R. B. (1996): "Labor Market Institutions and Earnings Inequality," New England Economic Review, 2(3), 157-168.

Goodman, A., And A. Shephard (2002): "Inequality and Living Standards in Great Britian: Some Facts," Briefing Note No. 19, Institute for Fiscal Studies, London.

Gottschalk, P., and T. M. Smeeding (1997): "Cross National Comparison of Earnings and Income Inequality," Journal of Economic Literature, 35(2), 633-678.

Gregg, P., And A. Manning (1997): "Skill-Biassed Change, Unemployment and Wage Inequality," European Economic Review, 41(6), 1173 - 1200.

Gundersen, C., M. LeBlanc, and B. Kuhn (1999): The Changing Food Assistance Landscape: The Food Stamp Program in a Post-Welfare Reform Environment, Agricultural Economics Report No. 773. United States Department of Agriculture.

Katz, L., And D. Autor (1999): "Changes in the Wage Structure and Earnings Inequality," in Handbook of Labor Economics, ed. by O. Ashenfelter, and D. Card, vol. 3, chap. 26, pp. 1643-1555. Elsevier, Amsterdam.

Krueger, A. B., And J.-S. Pischke (1998): "Observations and Conjectures on the U.S. Employment Miracle," in Third Public GAAC Symposium: Labor Markets in the USA and Germany, ed. by G. A. A. Council, pp. 99-126. Bonn.

Krugman, P. (1994): "Past and Prospective Causes of High Unemployment," in: Federal Reserve Bank of Kansas City (Editor) (1994): "Reducing Unemployment: Current Issues and Policy Options, Proceedings of a Symposium in Jackson Hole", WY, Kansas City, MO. 
(1995): "Growing World Trade: Causes and Consequences," Brookings Papers on Economic Activity, 1995(1), 327-362.

Levy, F., And R. J. Murnane (1992): "U.S. Earnings Levels and Earnings Inequality: A Review of Recent Trends and Proposed Explanations," Journal of Economic Literature, 30, 1333-1381.

Lindbeck, A., And D. J. Snower (1996): "Reorganization of Firms and Labor Market Inequality," American Economic Review, 86(2), 315-321.

Muthoo, A. (1999): Bargaining Theory with Applications. Cambridge University Press, Cambridge.

Muysken, J., And T. Zwick (2006): "Wage Divergence and Unemployment: The Impact of Wage Setting Power and Training Costs," Schmollers Jahrbuch, 126(1).

NiCKELL, S. (1997): "Unemployment and Labor Market Rigidities: Europe versus North America," Journal of Economic Perspectives, 11(3), 55-74.

Nickell, S., L. Nunziata, and W. Ochel (2005): "Unemployment in the OECD Since the 1960s. What Do We Know?," Economic Journal, 115, 1-27.

Nickell, S. J., And B. Bell (1996): "Changes in the Distribution of Wages and Unemployment in OECD Countries," American Economic Review, 86(2), 302-307.

Puhani, P. (2003): "A Test of the 'Krugman Hypothesis for the United States, Britain, and Western Germany," Discussion Paper No. 764, IZA, Bonn.

Reinberg, A., And M. Hummel (2002): "Qualifikationsspezifische Arbeitslosenquoten - Reale Entwicklung oder statistisches Artefakt?," IAB Werkstattbericht Nr. 04/2002, Nürnberg.

— (2005): "Vertrauter Befund: Höhere Bildung schützt auch in der Krise vor Arbeitslosigkeit," IAB Werkstattbericht Nr. 09/2005, Nürnberg.

Saint-Paul, G. (1997): Dual Labor Markets: A Macroeconomic Perspective. MIT Press, Cambridge.

Siebert, H. (1997): "Labor Market Rigidities: At the Root of Unemployment in Europe," Journal of Economic Perspectives, 11(3), 37-54.

Uccello, C. E., and L. J. Gallagher (1997): "General Assistance Programs: The State-Based Part of the Safety Net," New Federalism: Issues and Options for States, No. A-4, http://www.urban.org/url.cfm?ID=307036.

U.S. Census Bureau (1975 - 2004): Statistical Abstracts for the United States.

Veblen, T. (1899): The Theory of the Leisure Class. Allen and Unwin, London. 
Weiss, Y., and C. Fershtman (1998): "Social Status and Economic Performance: A Survey," European Economic Review, 42, 801-820.

Wood, A. (1998): "Globalisation and the Rise in Labor Market Inequality," Economic Journal, 108, 1463-1482. 